ISSN 2236-0859

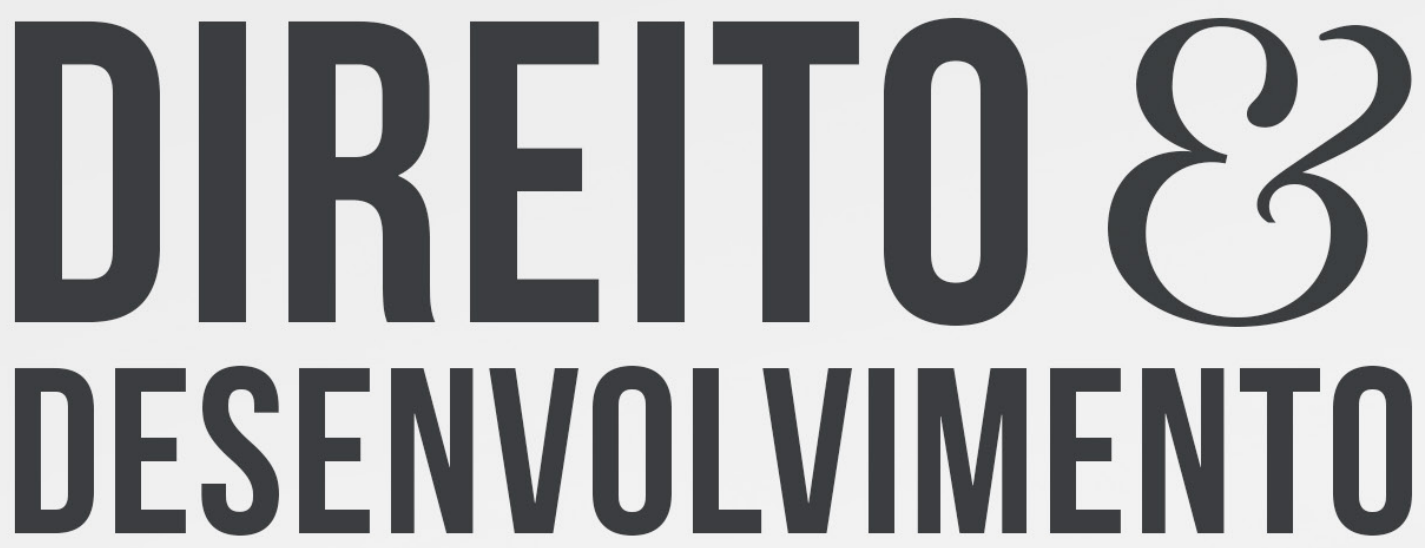

REVISTA DO PROGRAMA DE PÓS-GRADUAÇÃO EM DIREITO MESTRADO EM DIREITO E DESENVOLVIMENTO SUSTENTÁVEL

UMA ANÁLISE DO SUPERENDIVIDAMENTO A PARTIR

DE UMA PERSPECTIVA SOCIOAMBIENTAL E DO DIREITO AO MEIO AMBIENTE EQUILIBRADO

\author{
ANTONIO CARLOS EFING \\ CAROLINE JANAINA MENDES \\ JUSSARA MARIA LEAL DE MEIRELLES
}




\title{
UMA ANÁLISE DO SUPERENDIVIDAMENTO A PARTIR DE UMA PERSPECTIVA SOCIOAMBIENTAL E DO DIREITO AO MEIO AMBIENTE EQUILIBRADO
}

\author{
AN ANALYSIS OF SURVEILLANCE FROM A SOCIO- \\ ENVIRONMENTAL PERSPECTIVE AND BALANCED \\ ENVIRONMENTAL RIGHT
}

Recebido: 30/10/2018

Aprovado: 12/12/2019
Antonio Carlos Efing ${ }^{1}$

Caroline Janaina Mendes ${ }^{2}$

Jussara Maria Leal de Meirelles ${ }^{3}$

\section{RESUMO:}

O presente artigo tem por objetivo analisar o superendividamento para além de uma questão econômica, com uma análise voltada ao superendividado, sujeito que vivencia essa situação, analisando-se as causas desse fato, bem como as suas consequências e os seus possíveis tratamentos. Nessa perspectiva, é examinado em um primeiro momento, como ocorre o consumo na sociedade contemporânea. Em seguida, aborda-se como se dá o desenvolvimento de quadros patológicos devido ao superendividamento, bem como, a análise de como estas doenças podem gerar um consumo exacerbado, que conduz ao superendividamento. Por fim, concluise que se faz urgente uma reflexão acerca da necessidade de construção de regulamentação própria acerca do superendividamento no ordenamento jurídico brasileiro, visto o aumento significativo de indivíduos superendividados na sociedade atual, uma regulamentação que trate o superendividamento para além de uma questão econômica, com uma análise socioambiental voltada ao sujeito que vivência essa situação, analisando-se as suas origens, bem como as suas consequências e os seus possíveis enfrentamentos. Para a presente pesquisa, foi utilizado o método de abordagem científica dedutivo, o método procedimental histórico e as técnicas de pesquisa bibliográfica e documental.

Palavras-chave: Sociedade de Consumo. Consumismo. Superendividamento. Doenças. Capacidade Civil. Direito do Meio ambiente equilibrado. Proteção Socioambiental.

\footnotetext{
ABSTRACT:

The purpose of this article is to analyze super indebtedness beyond an economic question, with an analysis focused on the over-indebted, subject that experiences this situation, analyzing the causes of this fact, as well as its consequences and possible treatments. From this perspective, it is examined at first, as consumption in contemporary society. Then, it is approached how the development of pathological conditions due to the over-indebtedness, as well as, the

1 Doutor e Mestre em Direito pela PUC-SP, Mestre em Ciências Jurídicas pela UFPB. Professor Titular da Pontifícia Universidade Católica do Paraná (PUCPR).. Email: ace@eradv.com.br

2 Mestrando em Direito e Desenvolvimento Sustentável pelo Centro Universitário de João Pessoa (UNIPÊ) e pós-graduando em Direito Tributário. Advogado. Email: caroline.jmendes@hotmail.com

3 Doutora em Direito das Relações Sociais pela Universidade Federal do Paraná (UFPR). Professora titular de Direito Civil da Pontifícia Universidade Católica do Paraná (PUCPR). E-mail: jumeirelles29@gmail.com
} 
analysis of how these diseases can generate an exacerbated consumption, that leads to the super indebtedness. Finally, it is concluded that there is an urgent need to reflect on the need to build a proper regulation on super indebtedness in the Brazilian legal system, given the significant increase in super-indebtedness in today's society, a regulation that treats over-indebtedness beyond a question economic analysis with a socio-environmental analysis aimed at the subject who experiences this situation, analyzing the causes of this fact, as well as its consequences and possible treatments. For the present research, the method of deductive scientific approach, the historical procedural method and the bibliographic and documentary research techniques were used.

Keywords: Consumerism. Super indebtedness. Diseases. Civil capacity. Balanced environment.

\section{INTRODUÇÃO}

A sociedade contemporânea experimenta o ápice do movimento consumerista, a globalização e o desenvolvimento de novas tecnologias contribuem na fomentação do consumo desenfreado a tal ponto que são responsáveis hoje, pelo principal direcionamento do consumo das pessoas que fazem parte deste ambiente virtual.

E é nesse contexto, sob a influência das redes sociais, sob a influência da publicidade e da própria cultura da sociedade como um todo, que as pessoas deste século caminham por uma estrada desenfreada de consumo, onde o consumir significa "ser" alguém, significa dar um sentido a própria existência.

O consumo na sociedade atual ganha um significado simbólico de status, de significado da própria existência e de reconhecimento social. Diante deste ambiente, sentimentos de desejos insaciáveis e de ansiedade, só são um dos sentimentos gerados por esta onda consumerista. Sentimentos estes que não são somente o efeito, mas também o objetivo principal do movimento de consumo, uma vez que estes são à base do seu sucesso.

Diante destes fatos, surge uma outra causa aparente da sociedade de consumo, qual seja o endividamento ou o superendividamento, os quais são gerados por essa busca de satisfações e também, em muitos casos, gerados pela necessidade de obtenção de itens básicos de sobrevivência, como alimentos, água, luz, habitação, saúde, entre outros.

Ocorre que em alguns casos, o ciclo deste mercado pode se inverter, como é no caso, por exemplo, de alguns consumidores endividados ou superendividados, os quais por se encontrarem nesta situação, se sentem frustrados, em depressão e buscam justamente no consumo a autorealização pessoal, consumo este que gera mais dívidas, mais frustação de desejos, mais busca por saciedade de necessidades, tornando o ciclo de consumo um caminho sem volta.

Em alguns casos este endividamento pode chegar a tal ponto, que o consumidor de boa-fé se encontra sem meios de quitar suas dívidas presentes e futuras, se encontrando diante de um superendividamento, fato este que abala intensamente a vida dos afetados e dos que estão em seu entorno, causando um estado permanente de insegurança econômica, gerando baixa autoestima e podendo até mesmo desencadear problemas de saúde.

Verifica-se, portanto, que a sociedade contemporânea e a sua cultura influenciam de tal modo o cotidiano de seus cidadãos, que o ciclo de consumo se concretiza constantemente e aquilo que pode instigar o desejo de consumo para auto realização é o mesmo que mais tarde causará a ansiedade, a tristeza, a frustação e que será curado com o mesmo remédio, qual 
seja, o consumo em busca da realização de uma felicidade que já é previamente projetada para nunca ser inteiramente realizada.

Neste contexto, é possível observar que o enfrentamento da questão do superendividamento ainda é uma lacuna no ordenamento jurídico brasileiro, uma vez que o Código de Defesa do Consumidor, não trata especificamente dos casos de superendividamento e os outros institutos passíveis de aplicação ao caso, não tratam o problema como este deveria ser realmente tratado, ou seja, com uma análise específica das suas causas e efeitos, com a preservação da dignidade da pessoa humana.

Importante se faz observar a necessidade de consagração da dignidade da pessoa humana no caso em questão, uma vez que, corre-se o sério risco desse ambiente de dívidas e falta de recursos, levarem o sujeito superendividado a desenvolver quadros patológicos de ansiedade, depressão, e entre outras tantas doenças que podem ser geradas neste meio ambiente inseguro.

Como meio de reflexão para uma possível contribuição à construção de uma regulamentação própria do superendividamento, o trabalho propõe uma análise, a partir do direito constitucional a um meio ambiente equilibrado. Conforme explica Jussara Meirelles (Disponível em:<http://www.publicadireito.com.br/conpedi/manaus/arquivos/anais/bh/ jussara_maria_leal_de_meirelles.pdf $>$. Acesso em; 22 de jun de 2018), o meio ambiente equilibrado, "é aquele que dá condições de assegurar a qualidade de vida, nesta compreendida, evidentemente, a integridade psíquica de todos", segundo expõe a autora ainda, diversos quadros patológicos são desencadeados por fatores ambientais, decorrentes da vida atual nas grandes cidades, refletindo-se em um verdadeiro impacto ambiental. (MEIRELLES, Disponível em:<http://www.publicadireito.com.br/conpedi/manaus/arquivos/anais/bh/jussara_maria_ leal_de_meirelles.pdf $>$. Acesso em; 22 de jun de 2018.)

Diferente não é o caso, quando se fala de superendividamento, fato este que causa verdadeiro impacto ambiental na vida da pessoa que passa por essa situação, bem como para todos aqueles que estão em seu entorno.

A partir desta reflexão, verifica-se, a partir da análise do instituto da Incapacidade Acidental, previsto no Código Civil Português (Decreto-lei no 47.344 de 25 de novembro de 1966), que busca alcançar quem se encontra acidentalmente incapacitado por qualquer causa passageira que comprometa a sua faculdade intelectual e volitiva, sendo possível nestes casos, a anulação do ato jurídico praticado por esta pessoa.

Busca-se ainda, uma reflexão acerca da urgente necessidade de construção de uma regulamentação própria acerca do superendividamento no ordenamento jurídico brasileiro, visto o aumento significativo de indivíduos superendividados na sociedade atual, sejam estas situações geradas pela obtenção exacerbada de itens considerados supérfluos, pela obtenção de itens de primeira necessidade ou pelo empréstimo recorrente em instituições bancárias ou órgãos de crédito.

Isto posto, o tema a ser desenvolvido no presente estudo refere-se à necessidade de se analisar o superendividamento para além de uma questão econômica, com uma análise voltada ao superendividado, sujeito que vivência essa situação, analisando-se as causas desse fato, bem como as suas consequências e os seus possíveis tratamentos. Assim, ao final desta pesquisa, pretende-se responder ao seguinte questionamento: como o superendividamento poderia ser tratado a partir de um olhar socioambiental, que valoriza a pessoa como sujeito em todas as suas dimensões, buscando-se a consagração da dignidade da pessoa humana?

Para tanto, o trabalho foi organizado em três itens, tendo início com a análise do consumo na sociedade contemporânea e no desenvolvimento de quadros patológicos devido ao superendividamento, bem como, a análise de como estas doenças podem gerar o efeito 
contrário. Na sequência verificou-se o superendividamento a partir de uma perspectiva de análise da capacidade civil e do meio ambiente equilibrado.

Para isso, foi utilizado o método de abordagem científica dedutivo, o método procedimental histórico e as técnicas de pesquisa bibliográfica e documental, com a análise de livros, artigos científicos, teses e dissertações sobre o assunto.

\section{COMO SE DESENVOLVE O CONSUMISMO NA SOCIEDADE CONTEMPORÂNEA}

O desejo de fazer parte de um determinado grupo social ou de uma classe social, de consumir determinadas marcas e de ter acesso a produtos exclusivos, sempre esteve presente nos sonhos da grande maioria das pessoas que fazem parte da sociedade contemporânea, uma sociedade que conforme explica Maristela Denise Marques de Souza ( 2018), é a sociedade que experimenta o ápice do movimento consumerista, de tal maneira que esse consumo interfere diretamente nas relações sociais, familiares e na identidade do "homus consumos".

O século XX foi marcado pela consolidação do capitalismo industrial como modo de produção. Através deste sistema, a pretexto do desenvolvimento, as pessoas, sobretudo empresas, têm utilizado grandes quantidades de recursos naturais, causando a instabilidade ambiental e a desorganização ecológica. Consequentemente, danos ambientais em grande escala tem ocorrido. (Paffarini, Colognese e Hamel, 2017)

A globalização e o desenvolvimento de novas tecnologias contribuíram e continuam a contribuir na fomentação desse consumo desenfreado. E nesse contexto, o surgimento das chamadas "redes sociais" na internet, possuem um papel cada vez mais fundamental nesta sociedade, pois, quando se trata de influenciar o modo de vida de seus "seguidores" ou participantes, estas redes possuem papel fundamental no direcionamento do consumo destas pessoas.

A influência das redes sociais é tamanha que muitos dos seus participantes passam a consumir produtos, baseados somente na influencia que seus ídolos e bloggers possuem sobre seus hábitos. Pessoas essas que realizam postagens recorrentes em seus perfis pessoais, usando produtos que são patrocinados por marcas, como modo de dar publicidade aqueles itens de consumo.

Além de criar um movimento de influência de consumo direcionado, as redes sociais propiciam ainda, a sensação de vivência no "mundo perfeito", possibilitando a seus participantes a sensação de que tudo é possível naquele ambiente, de que ninguém que está naquele espaço possui problemas familiares e/ou pessoais, uma vez que todos só postam os acontecimentos bons de sua rotina, além de gerar um efeito em massa de que todos naquele ambiente possuem acesso aos últimos lançamentos do mercado, às melhores roupas, aos melhores sapatos, bolsas, eletrônicos, bem como o acesso aos melhores e mais requintados locais de lazer.

É nesse ambiente então, que a sociedade contemporânea se desenvolve, em um ambiente de "falsas aparências", no qual aquele que pensa não ter "nada", deseja consumir um determinado produto ou hábito, baseado na influência daquele que finge ter alguma coisa.

E é assim, sob a influência destes ambientes de redes sociais, sob a influência da publicidade e da própria cultura da sociedade como um todo, que as pessoas deste século caminham por uma estrada desenfreada de consumo, onde o consumir significa "ser" alguém, significa dar um sentido a própria existência.

Inês Hennigen ao analisar as lições de Jean Baudrillard (Disponível em: <http://pepsic. bvsalud.org/pdf/malestar/vion4/o6.pdf >. Acesso em: 22 de jun de 2018), comenta que a posse de 
determinados bens está diretamente vinculado ao seu aspecto simbólico, que podem significar status e poder, pois evidenciam que cada vez mais, mercadorias são concebidas não somente como objetos, mas meios que possibilitam identidade, pertencimento e reconhecimento social, fazendo com que o consumo passe a ser considerado o motor e matriz das relações sociais.

Diante deste contexto, sentimentos de desejos insaciáveis e de ansiedade, só são um dos sentimentos gerados por esta onda consumerista. Sentimentos estes que não são somente o efeito, mas também o objetivo principal do movimento de consumo, uma vez que estes são à base do seu sucesso. Conforme explica Zygmunt Bauman (2008):

A instabilidade dos desejos e a insaciabilidade das necessidades, assim como a resultante tendência ao consumo instantâneo e à remoção, também instantânea, de seus objetos, harmonizam-se bem com a nova liquidez do ambiente em que as atividades existenciais foram inscritas e tendem a ser conduzidas no futuro previsível.

Verifica-se, portanto, que diante de uma sociedade contemporânea, a realidade do consumo ganha duas facetas, uma onde o incentivo a saciabilidade de desejos é infindável e a outra, onde os incentivos a sentimentos como a ansiedade e a satisfação de necessidades se tornam a máquina locomotora desse ciclo. Neste sentido, alerta Bauman (2008)

\footnotetext{
A sociedade de consumo tem como base de suas alegações a promessa de satisfazer desejos humanos em um grau que nenhuma sociedade do passado pôde alcançar, ou mesmo sonhar, mas a promessa de satisfação só permanece sedutora enquanto o desejo continua insatisfeito; mais importante ainda, quando o cliente não está "plenamente satisfeito" - ou seja, enquanto não se acredita que os desejos que motivaram e colocaram em movimento a busca da satisfação e estimularam experimentos consumistas tenham sido verdadeira e totalmente realizados.
}

Bauman (2009) expõe ainda, que sem a frustação dos desejos, a demanda pelo consumo diminuiria rapidamente e a economia perderia sua impulsão.

É diante de todo este contexto então, que surge uma outra causa aparente da sociedade de consumo, qual seja o endividamento ou o superendividamento, o quais são gerados por essa busca de satisfações e também, em muitos casos, gerados pela necessidade de obtenção de itens básicos de sobrevivência, como alimentos, água, luz, habitação e entre outros.

Neste sentido, Simone Artifon e Maristela Piva (Disponível em:<http://www.psicologia. pt/artigos/textos/Ao771.pdf >. Acesso em; 19 de jun de 2018) destacam que "para pesquisadores da psicologia econômica e da neuroeconomia, o endividamento está ligado especialmente à falta de autocontrole e à busca por uma compensação, um alívio para impulsos".

Sustentam Antônio Carlos Efing, Gabriele Polewka e Olenka Woolcott Oyague (2015) que o endividamento ou o superendividamento, se confundem com o próprio desenvolvimento da sociedade de consumo, fazendo parte da vida em sociedade nos dias atuais, superendividamento esse, que pode ser defino como expõe Fernanda Moreira Cezar (2007), como a impossibilidade do consumidor pessoa física, de boa-fé, pagar todas as suas dívidas de consumo, sejam elas atuais ou futuras, (CEZAR, 2007) sendo tais situações agravadas devido às diversas possibilidades de concessão de créditos e financiamentos disponíveis no mercado, concessões estas que na sua grande maioria ocorrem de modo irresponsável, sabendo-se que os seus consumidores não têm condições de saldá-las antes mesmo da contratação destes serviços. (EFING e OYAGUE, 2015)

Dessa forma que o mercado do consumo se desenvolve, sendo esta uma das causas de movimento e impulsão deste mercado.

Ocorre que em alguns casos, o ciclo deste mercado pode se inverter, como é no caso, por exemplo, dealguns consumidores endividados ou superendividados, os quais por se encontrarem 
nesta situação, se sentem frustrados, em depressão e buscam justamente no consumo a auto realização pessoal, conforme explica Simone Artifon e Maristela Piva (Disponível em:< http:// www.psicologia.pt/artigos/textos/Ao771.pdf>. Acesso em; 19 de jun de 2018), "o endividamento não é resultado de um fato isolado, contudo, a aquisição de novas dívidas, prioriza o consumo de itens supérfluos, o que evidencia a existência de fatores simbólicos no ensejo por comprar bens de consumo trazendo valor ao eu". As autoras relatam ainda, ao citar a obra "A revolução da esperança: por uma tecnologia humanizada" de E. Fromm, que o consumo tem sua origem na sensação de vazio interior, no desespero, na confusão, no temor, gerando assim, sentimentos de fragilidade, frustração, fracasso, sensação de inaptidão para auto realização pessoal (ARTIFON e PIVA, Disponível em:< http://www.psicologia.pt/artigos/textos/Ao771.pdf >. Acesso em; 19 de jun de 2018), consumo este que gera mais dívidas, mais frustação de desejos, mais busca por saciedade de necessidades, tornando o ciclo de consumo um caminho sem volta.

\section{O SUPERENDIVIDAMENTO GERA DOENÇAS E DOENÇAS GERAM O SUPERENDIVIDAMENTO}

Diversos são os casos que conduzem o consumidor ao endividamento, e em alguns casos este endividamento pode chegar a tal ponto, que até mesmo as necessidades mais básicas da vida deste consumidor podem ser impactadas pela falta de recurso para supri-las. É a partir deste momento então, quando o consumidor de boa-fé se encontra sem meios de quitar suas dívidas presentes e futuras (CEZAR, 2007), devido a um fato superveniente, quando este não possui perspectivas para saldar suas dívidas, que o superendividamento pode ser exemplificado. Pois, o superendividamento parte da premissa de que aquele endividamento somente ocorreu, porque de fato o consumidor se encontra em tal situação, que mesmo que desejasse quitar suas dívidas, não poderia fazê-lo, pois não tem poder aquisitivo para tanto.

Antônio Carlos Efing, Gabriele Polewka e Olenka Woolcott Oyague (2015) explicam que a doutrina divide os superendividados em duas categorias, qual seja os superendividados passivos, aqueles que não conseguem pagar suas dívidas por situações alheias as suas vontades, devido, por exemplo, a um desemprego inesperado, divórcio ou doença e os superendividados ativos, que são aqueles que consomem de forma consciente, sabendo desde o início que não conseguiram arcar com aquela dívida ou de forma inconsciente, que são os casos em que o consumidor acredita honestamente que conseguirá pagar aquela dívida, mas que falha ao honrar com sua obrigação, devido ao fato de não ter calculado corretamente o impacto que aquela dívida causaria em seu orçamento.

Os autores complementam que "as causas do superendividamento e as suas consequências abalam intensamente a vida dos afetados e de seu entorno, criando um círculo vicioso difícil de ser rompido". (EFING e OYAGUE, 2015). Explicam que o consumidor com o superendividamento começa a viver em estado permanente de insegurança econômica, sendo atingido pela baixa autoestima, podendo até mesmo desenvolver problemas de saúde, visto a tentativa de manter o mesmo padrão de vida ou até mesmo a tentativa de esconder da família o problema financeiro, (EFING e OYAGUE, 2015) o que só agrava ainda mais a repercussão interna deste problema.

Nessa perspectiva, Ray Earwicker (Disponível em: <http://www.health-inequalities. eu/wp-content/uploads/2016/o5/Problem-debt-and-health.pdf >. Acesso em: 05 de jul de 2018) relata que diversas variáveis contribuem para a "causa das causas" de doenças, essas incluem emprego, educação, habitação, meio ambiente, transporte, crime, pobreza e renda. 
Ainda, para Ray Earwicker (Disponível em: <http://www.health-inequalities.eu/ wp-content/uploads/2016/o5/Problem-debt-and-health.pdf $>$. Acesso em: 05 de jul de 2018) o endividamento é elemento essencial na vida da sociedade moderna e que a disponibilidade e o acesso a crédito são vitais para a economia e para manutenção de padrões de vida, que estes somente se tornam um problema, quando passa haver pelo consumidor, dificuldades para a sua quitação. Nestes casos, a dívida pode começar a gerar implicações tanto na saúde física, como na saúde mental dos consumidores, podendo promover doenças ligadas à ansiedade e a depressão. $\mathrm{O}$ suicídio pode estar ligado à dificuldade de quitação de dívidas, tamanho o impacto que estas podem ter sobre a vida da pessoa que as contraíram.

Neste contexto, Simone Artifon e Maristela Piva (Disponível em:< http://www. psicologia.pt/artigos/textos/Ao771.pdf $>$. Acesso em; 19 de jun de 2018) relatam que ao realizarem uma pesquisa qualitativa no Balcão do Consumidor, projeto de extensão da Faculdade de Direito da Universidade de Passo Fundo (UPF) no Estado do Rio Grande do Sul, tendo como participação seis entrevistados, que contraíram dívidas significativas em relação ao seu orçamento, verificaram que em resposta a uma das perguntas do questionário, qual seja, "Qual o significado das compras que foi fazendo em tua vida?” o conteúdo obtido nas respostas dos entrevistados demonstra que muitos acreditam que o bem-estar efêmero decorre do consumo de bens e que este proporciona condição de independência, prazer, liberdade e felicidade. As autoras relatam ainda, que diante das falas percebe-se que o consumo de objetos sacia ilusoriamente a vontade e preenchem o vazio interior, visto que muitos sujeitos comentaram não querer guardar dinheiro, por não saber o dia de manhã, o que evidencia segundo as autoras, a dificuldade de lidar com frustrações, expressando aspectos da subjetividade contemporânea, como o individualismo, o prazer imediato e a dificuldade de planejar um futuro.

Verificam as autoras ainda, que ao questionarem aos entrevistados "Como te sentes

depois da compra?" a maioria respondeu que se sente aliviado, pois compraram o que desejavam, ao contrário do que responderam à pergunta "Como te sentes geralmente antes de comprar algo que desejas?” onde a autoras evidenciaram sentimentos de dúvidas e ansiedade. (ARTIFON e PIVA, Disponível em:< http://www.psicologia.pt/artigos/textos/Ao771.pdf>. Acesso em; 19 de jun de 2018). Diante das respostas as autoras revelam que a o ato de comprar produz estados fugazes de prazer e satisfação, mas que atrelado a isso há também "o despertar de inúmeras ansiedades decorrentes da conscientização de orçamento desprovido, quando ficam apreensivos ao pensar como vão pagar", o que segundo as autoras, demonstra claramente como funciona os desejos alienados de consumo, os quais quando satisfeitos, são rapidamente substituídos por outros por meio do ritmo incessante do consumismo. (ARTIFON e PIVA, Disponível em:< http://www.psicologia.pt/artigos/textos/Ao771.pdf $>$. Acesso em; 19 de jun de 2018)

Portanto, é possível observar, que a sociedade contemporânea e a sua cultura influenciam de tal modo o cotidiano de seus cidadãos, que o ciclo de consumo se concretiza constantemente e aquilo que pode instigar o desejo de consumo para auto realização é o mesmo que mais tarde causará ansiedade, tristeza, frustação e que será curado com o mesmo remédio, que será o consumo em busca da realização de uma felicidade que já é previamente projetada para nunca ser inteiramente realizada. 


\section{O SUPERENDIVIDAMENTO E UMA ANÁLISE DA CAPACIDADE CIVIL SOB A PERSPECTIVA DE UM MEIO AMBIENTE EQUILIBRADO}

A sociedade contemporânea fez emergir um problema social antes não verificado em outras sociedades, qual seja o superendividamento de seus cidadãos, gerado pelo consumo exacerbado na busca de felicidade e de saciedade de desejos, necessidades essas produzidas e incentivadas pela própria cultura deste modelo de sociedade.

Conforme relatam Antônio Carlos Efing, Gabriele Polewka e Olenka Woolcott Oyague (2015) o superendividamento transforma-se em um problema social, quando retira dos devedores a sua dignidade, condenando-os à exclusão social, fazendo-os arrastar por toda uma vida uma dívida insolúvel.

Sob esta perspectiva os autores explicam ainda, que a Sociedade e o Estado necessitam encontrar respostas que atendam em termos de justiça e efetividade esta "classe de consumidores", visto a necessidade de se garantir o respeito à dignidade humana e ao próprio desenvolvimento econômico sustentável.(EFING, POLEWKA e OYAGUE, 2015)

Atualmente o sistema jurídico brasileiro apresenta em seu ordenamento alguns meios de tratamento da questão da pessoa superendividada, ocorre que nenhum destes meios soluciona efetivamente as causas e os efeitos do superendividamento, não havendo legislação específica acerca do assunto.

Neste sentido, é possível verificar que o ordenamento jurídico dispõe de um Código próprio para a Defesa do Consumidor, o qual possui como objetivo a tutela das relações de consumo, a defesa do consumidor diante de um mercado econômico, ocorre que quando da sua promulgação, o Código não previu tamanho crescimento e desenvolvimento de diversas modalidades de transações e vendas, bem como modo de concessões de crédito (EFING, POLEWKA e OYAGUE, 2015), assim, conforme enfatizam os autores "o enfrentamento do problema se dá através da criatividade dos operadores do Direito que buscam soluções nos instrumentos legais existentes, considerados insuficientes diante da magnitude e características do problema", uma vez que mesmo o Código de Defesa do Consumidor, não tratou especificamente dos casos de superendividamento.

Outro instituto bastante debatido quando se toca no teor da discussão do superendividamento, se refere ao artigo 1.052 do novo Código de Processo Civil, o qual trata da Insolvência Civil, sendo que tal artigo manteve o mesmo conteúdo do artigo 748 e seguintes do antigo Código de Processo Civil (BRASIL, Disponível em:< http://www.planalto.gov.br/ ccivil_03/_ato2015-2018/2015/lei/l13105.htm>. Acesso em: o5 de jul de 2018).

Deste modo, segundo o instituto da Insolvência Civil, a insolvência se dá "toda vez que as dívidas excederem à importância dos bens do devedor" (BRASIL, Disponível em:< http://www.planalto.gov.br/ccivil_03/_ato2015-2018/2015/lei/l13105.htm>. Acesso em: o5 de jul de 2018), o que significa em outros termos, assegurar ao credor, os direitos dispostos nos artigos 749 à 753 do antigo Código de Processo Civil, quais sejam, dentre outros, antecipar o vencimento das dívidas do superendividado, arrecadar todos os bens suscetíveis de penhora, quer seja os bens atuais, como os futuros, bem como despir o devedor da administração de seus bens até a liquidação total da massa. (BRASIL, Disponível em: $<$ http://www.planalto.gov. br/ccivil_03/LEIS/L5869.htm\#livroiitituloiv >. Acesso em: 05 de jul de 2018). Conforme expõe Tais Hemann da Rosa e Fábio Siebeneichler de Andrade (ROSA e ANDRADE, Disponível em: $<$ file:///C:/Users/caroline/Downloads/4508-15663-1-PB\%2o(2).pdf>. Acesso em: o5 de jul. de 2018), é possível observar que a "figura da insolvência é limitada, tendo um propósito restrito a organizar o procedimento de cobrança de débitos do devedor que incidiu na situação de insolvência”. 
Em outros termos, é possível dizer, que o Instituto da Insolvência também não seria o instituto mais adequado para aplicação no caso dos superendividados, uma vez que consoante a este assunto, explica Tais Hemann da Rosa e Fábio Siebeneichler de Andrade (Disponível em: < file://C:/Users/caroline/Downloads/4508-15663-1-PB\%2o(2).pdf>. Acesso em: 05 de jul. de 2018), que "a disciplina da problemática do superendividamento se apresenta como diferenciada, e mais ambiciosa, na medida em que pretende a adoção de medidas para efetivamente proteger o devedor, excepcionando o princípio do pact sun servanda", sendo importante neste caso, porém, a verificação de quando deve esta proteção incidir ou não ao particular devedor, verificando-se nestes casos se houve um superendividamento passivo ou ativo inconsciente, os quais normalmente são compreendidos como passíveis de incidência jurídica. (EFING, POLEWKA e OYAGUE, 2015)

Diante deste debate, Antônio Carlos Efing, Gabriele Polewka e Olenka Woolcott Oyague (2015) ao analisarem o Projeto de Lei do Superendividamento no $283 / 2012$, colocam que um caminho para combater o superendividamento, seria o entendimento previsto no referido projeto, o qual postula como solução para estes casos, iniciativas que busquem promover o acesso ao crédito de modo responsável e à educação financeira do consumidor, de forma a evitar a exclusão social e o comprometimento do mínimo existencial na vida deste devedor, de modo que as condições mínimas de dignidade destas pessoas, como o acesso a água, alimentação, luz, saúde, moradia e educação não sejam afetadas diante de tal situação.

Deste modo, importante se faz ressaltar, a necessidade de preservação da dignidade da pessoa humana diante de casos de superendividamento, direito este consagrado como princípio constitucional intransponível, independentemente do caso em que questão. Pois, caso assim não o seja, corre-se o sério risco desse ambiente de dívidas e falta dos recursos mais básicos de sobrevivência, levarem o sujeito superendividado a desenvolver quadros patológicos de ansiedade, depressão transtorno do pânico e entre outras tantas doenças que podem ser geradas neste meio ambiente inseguro.

Nestes termos, expõe Jussara Maria Leal de Meirelles que a Constituição Federal em seu artigo 225 protege o meio ambiente equilibrado, que segundo a autora "é aquele que dá condições de assegurar a qualidade de vida, nesta compreendida, evidentemente, a integridade psíquica de todos" (MEIRELLES, Disponível em:<http://www.publicadireito.com.br/conpedi/ manaus/arquivos/anais/bh/jussara_maria_leal_de_meirelles.pdf $>$. Acesso em; 22 de jun de 2018.), segundo expõe autora ainda, diversos quadros patológicos são desencadeados por fatores ambientais, decorrentes da vida atual nas grandes cidades, refletindo-se em um verdadeiro impacto ambiental, diferente não é o caso, quando se fala no superendividamento, fato este que causa um verdadeiro impacto ambiental na vida da pessoa que passa por essa situação, bem como para todos aqueles que estão em seu entorno. Assim, esclarece a autora:

O meio ambiente ecologicamente equilibrado e essencial à sadia qualidade de vida, assegurado constitucionalmente, deve ser, sem dúvida, o que se demonstra apto a manter a integridade psíquica de todos. Se o meio ambiente em que se vive não oferece condições, para tanto, necessário realizar-se uma leitura compreensiva de eventuais consequências até desastrosas que esse mesmo meio ambiente pode causar na vida de cada um.

Sob esse ponto de vista, explica a autora que o medo é o resultado psicológico mais frequente decorrente da vida na sociedade atual, apresentando-se com maior evidência e em diferentes graus de intensidade, por meio da ansiedade, da angústia, do pânico, da fobia e entre outros, sendo indiscutível o componente ambiental que influência determinadas doenças, mesmo que em alguns casos, tais quadros patológicos possam estar vinculados a fatores pessoais individuais. (MEIRELLES, Disponível em:<http://www.publicadireito.com.br/ 
conpedi/manaus/arquivos/anais/bh/jussara_maria_leal_de_meirelles.pdf $>$. Acesso em; 22 de jun de 2018). Componente ambiental este, que no caso do superendividamento é gerado pela situação de insegurança do devedor em se ver impotente diante de uma situação de dívidas impossíveis de serem saldadas. Jussara Meirelles ainda arremata:

Pessoas não são descartáveis, evidentemente. No entanto, em pânico, ansiosas ou estressadas após um trauma, não produzem os resultados que a sociedade produtiva espera delas. E então, o que se vê? A mesma sociedade que contribuiu para o estado em que elas se encontram, munindo-se de regras e fundamentos para deixá-las, de certa forma e em certa medida, à parte.

Diante deste quadro poder-se-ia dizer que tais pessoas, atingidas por estas doenças, diante de um caso de superendividamento que leve os devedores a ficarem a margem de sua própria dignidade, poderiam ter sua manifestação de vontade considerada prejudicada, tendo em vista que uma pessoa em pânico, não manifesta seu consentimento com a atenção devida, nem seu consentimento é tido como livre. (MEIRELLES, Disponível em:<http://www. publicadireito.com.br/conpedi/manaus/arquivos/anais/bh/jussara_maria_leal_de_meirelles. pdf $>$. Acesso em; 22 de jun de 2018.)

Além de tal fato, importante recordar, que conforme explica Simone Artifon e Maristela Piva (Disponível em:< http://www.psicologia.pt/artigos/textos/Ao771.pdf>. Acesso em; 19 de jun de 2018), o consumo e o endividamento estão ligados especialmente à falta de autocontrole e à busca por um alívio de impulsos, que trazem uma valorização do eu, consumo este que se revela em uma dificuldade de lidar com frustações e de planejar um futuro, neste sentido, é importante observar que no caso do sujeito superendividado sua manifestação de vontade ao contrair novas dívidas, quando este já se encontra em uma situação de endividamento, merece uma análise pormenorizada, para que seja verificado se este de fato possuía discernimento de suas atitudes quando assumia mais uma divida, ou se este agia sob influência de seus sentimentos, em busca de uma realização pessoal.

Para este contexto de quadros patológicos, explica Jussara Meirelles (Disponível em:<http://www.publicadireito.com.br/conpedi/manaus/arquivos/anais/bh/jussara_maria_ leal_de_meirelles.pdf $>$. Acesso em; 22 de jun de 2018) que sob um ponto de vista prático, a proteção de tais pessoas, poderia se dar pela aplicação do regime jurídico das capacidades civis, o qual, foi reconstruído atualmente a partir da Convenção de Nova York e das mudanças realizadas no Estatuto da Pessoa com Deficiência, ocorre que com aplicação de tal regime estaria se correndo o risco, de mais uma vez, colocar a margem da sociedade estas pessoas que vivem sob a condição de superendividadas, punindo mais uma vez aos que já padecem de alguns dos efeitos mais devastadores da vida contemporânea. Explica a autora, que nas hipóteses de ansiedade, medo ou estresse, poder-se-ia argumentar uma incapacidade acidental.

A Incapacidade Acidental é um instituto jurídico previsto no Código Civil Português (Decreto-lei no 47.344 de 25 de novembro de 1966), que busca alcançar quem se encontra acidentalmente incapacitado por qualquer causa passageira que comprometa a sua faculdade intelectual e volitiva, sendo possível nestes casos, a anulação do ato jurídico praticado por esta pessoa. Tal incapacidade é caracterizada somente durante os momentos em que se verificam as suas causas, explica Jussara Meirelles que esta incapacidade "está adstrita a um determinado ato, para o qual o indivíduo não apresentava condições mentais de manifestar livremente a sua vontade. E existe apenas durante os momentos em que é possível verificar suas causas. Para, além disso, em quaisquer outras situações, a pessoa é considerada perfeitamente capaz". (MEIRELLES, Disponível em:<http://www.publicadireito.com.br/conpedi/manaus/arquivos/ anais/bh/jussara_maria_leal_de_meirelles.pdf $>$. Acesso em; 22 de jun de 2018.) 
Importante acentuar que tal nulidade do ato jurídico realizado só se torna apto quando o fato é notório ou conhecido pela outra parte, sendo que o notório se enfatiza, como o fato que uma pessoa de normal diligência teria podido notar. (MEIRELLES, Disponível em:<http://www. publicadireito.com.br/conpedi/manaus/arquivos/anais/bh/jussara_maria_leal_de_meirelles. pdf $>$. Acesso em; 22 de jun de 2018.)

A notoriedade de tais situações são naturalmente difíceis de serem verificadas, expõe Jussara Meirelles:

\begin{abstract}
Imagine-se a dificuldade de se comprovar o conhecimento, pela outra parte, de sintomas como os de ansiedade, estresse pós-traumático e o medo patológico, que podem ou não ser percebidos, até porque, em alguns casos, no afã de evitar constrangimentos maiores, são disfarçados por nuances comportamentais, até socialmente aceitáveis, somente evidenciando-se em casos mais severos.
\end{abstract}

Quando se fala em transtornos derivados do superendividamento, também pode ser verificada está dificuldade, principalmente nos casos de consumo derivados de uma busca de realização pessoal, contudo, quando se fala em empréstimos e concessões de financiamentos esse quadro poderia ser facilmente verificado pelas agências bancárias e órgãos de concessão de crédito, devido ao nível de informações integradas destes órgãos, o que geraria facilmente uma nulidade destes negócios com base em uma Incapacidade Acidental.

Contudo, verifica-se que no Brasil a regulação da nulidade destes negócios jurídicos ocorre de modo diferente, não havendo ainda, uma atenção especial ao sujeito superendividado. Fato este que se evidencia como de urgente regulamentação e atenção, devido ao aumento significativo de superendividados na sociedade atual, sejam estas situações de endividamento geradas pela obtenção exacerbada de itens considerados supérfluos, seja pela obtenção de itens de primeira necessidade ou pelo empréstimo recorrente em instituições bancárias ou órgãos de crédito.

Verifica-se ainda, a necessidade de uma regulamentação que conceda ao superendividado uma análise muito maior do que uma análise puramente econômica, mas uma análise socioambiental, que considere este sujeito em todas as suas dimensões, com todas as suas especificidades, uma regulamentação que compreenda não somente a causa, mas também os efeitos desta situação de superendividamento na vida destas pessoas, como expõe Jussara Maria Leal de Meirelles (MEIRELLES, Disponível em:<http://www.publicadireito.com. br/conpedi/manaus/arquivos/anais/bh/jussara_maria_leal_de_meirelles.pdf $>$. Acesso em; 22 de jun de 2018.), se faz importante reler categorias, revisar os conceitos, refletir "a respeito das disposições legais e dos fatos, sob o manto de valores tão fortes como a dignidade e a solidariedade. Somente assim é possível alcançar-se a compreensão verdadeira de quem, do quê e em que medida se pretende proteger".

\title{
5. CONSIDERAÇÕES FINAIS
}

Diante dos apontamentos realizados, é possível chegar a algumas conclusões:

a) A sociedade experimenta o ápice do movimento consumerista, de tal maneira que esse consumo interfere diretamente nas relações sociais e familiares. (SOUZA, 2018). A globalização e o desenvolvimento de novas tecnologias contribuíram e continuam a contribuir na fomentação desse consumo desenfreado. O surgimento das chamadas "redes sociais" na internet, possuem um papel cada vez mais fundamental nesta sociedade, pois, direcionam o consumo das pessoas neste ambiente virtual. 
E é diante deste contexto, que a sociedade contemporânea se desenvolve, sob a influência de redes sociais, sob a influência da publicidade e da própria cultura da sociedade como um todo, caminhando por uma estrada desenfreada de consumo, onde o consumir significa "ser" alguém, significa dar um sentido a própria existência.

Sentimentos de desejos insaciáveis e de ansiedade, só são um dos sentimentos gerados por esta onda consumerista. Sentimentos estes que não são somente o efeito, mas também o objetivo principal do movimento de consumo, uma vez que estes são à base do seu sucesso.

Outra causa aparente da sociedade de consumo é o aparecimento cada vez mais recorrente do endividamento ou o superendividamento, o quais são gerados por essa busca de satisfações e também, em muitos casos, gerados pela necessidade de obtenção de itens básicos de sobrevivência. Ocorre que em alguns casos, o ciclo deste mercado pode se inverter, como é no caso, por exemplo, de alguns consumidores endividados ou superendividados, os quais por se encontrarem nesta situação, se sentem frustrados, em depressão e buscam justamente no consumo a auto realização pessoal, consumo este que gera mais dívidas, mais frustação de desejos, mais busca por saciedade de necessidades, tornando o ciclo de consumo um caminho sem volta.

b) O superendivadamento parte da premissa de que o endividamento somente ocorreu, porque de fato o consumidor se encontra em tal situação, que mesmo que desejasse quitar suas dívidas, não poderia fazê-lo, pois não tem poder aquisitivo para tanto. Diante desta situação, o endividado começa a viver em estado permanente de insegurança econômica, sendo atingido pela baixa autoestima, podendo até mesmo desenvolver problemas de saúde. Devido a dificuldade de quitação de sua dívidas.

Observa-se que a sociedade contemporânea e a sua cultura influenciam de tal modo o cotidiano de seus cidadãos, que o ciclo de consumo se concretiza constantemente e aquilo que pode instigar o desejo de consumo para auto realização é o mesmo que mais tarde causará ansiedade, tristeza, frustação e que será curado com o mesmo remédio, que será o consumo em busca da realização de uma felicidade que já é previamente projetada para nunca ser inteiramente realizada.

c) Atualmente o sistema jurídico brasileiro apresenta em seu ordenamento alguns meios de tratamento da questão da pessoa superendividada, tais como os princípios e direitos previstos no Código de Defesa do Consumidor, bem como, o instituto da Insolvência Civil previsto no artigo 1.052 do novo Código de Processo Civil, disciplinado pelo artigo 748 e seguintes do antigo Código de Processo Civil. Ocorre, que nenhum destes meios soluciona efetivamente as causas e os efeitos do superendividamento, não havendo legislação específica acerca do assunto.

Deste modo, a partir da análise da autora Jussara Maria Leal de Meirelles (MEIRELLES, Disponível em:<http://www.publicadireito.com.br/conpedi/manaus/arquivos/anais/bh/ jussara_maria_leal_de_meirelles.pdf>. Acesso em; 22 de jun de 2018), se propõe uma leitura do superendividamento e de suas consequências ao superendividado, a partir do artigo 225 da Constituição Federal, o qual, estabelece a proteção do meio ambiente equilibrado, que segundo a autora "é aquele que dá condições de assegurar a qualidade de vida, nesta compreendida, evidentemente, a integridade psíquica de todos".

Sob esse ponto de vista, explica a autora que o medo é o resultado psicológico mais frequente decorrente da vida na sociedade atual, apresentando-se com maior evidência e em diferentes graus de intensidade, por meio da ansiedade, da angústia, do pânico, da fobia e entre outros, sendo indiscutível o componente ambiental que influência determinadas doenças, mesmo que em alguns casos, tais quadros patológicos possam estar vinculados a fatores pessoais individuais. (MEIRELLES, Disponível em:<http://www.publicadireito.com.br/ 
conpedi/manaus/arquivos/anais/bh/jussara_maria_leal_de_meirelles.pdf $>$. Acesso em; 22 de jun de 2018.). Componente ambiental este, que no caso do superendividamento é gerado pela situação de insegurança do devedor em se ver impotente diante de uma situação de dívidas impossíveis de serem saldadas. Diante deste quadro, a autora relata que tais pessoas, atingidas por estas doenças, poderiam ter sua manifestação de vontade consideradas prejudicada, tendo em vista que uma pessoa em pânico, não manifesta seu consentimento com a atenção devida, nem seu consentimento é tido como livre. O que diante de um caso de superendividamento, também poderia ser assim compreendido, uma vez que os devedores ao ficar a margem de sua própria dignidade, poderiam ter sua manifestação de vontade também considerada prejudicada.

Para este contexto de quadros patológicos, explica Jussara Meirelles (Disponível em:<http://www.publicadireito.com.br/conpedi/manaus/arquivos/anais/bh/jussara_maria_ leal_de_meirelles.pdf $>$. Acesso em; 22 de jun de 2018) que sob um ponto de vista prático, a proteção de tais pessoas, poderia se dar pela aplicação do regime jurídico das capacidades civis, ressalta, contudo, que com aplicação de tal regime estaria se correndo o risco, de mais uma vez, colocar a margem da sociedade estas pessoas que vivem sob a condição de superendividadas, punindo mais uma vez aos que já padecem de alguns dos efeitos mais devastadores da vida contemporânea, de tal modo, explica a autora, que nas hipóteses de ansiedade, medo ou estresse, poder-se-ia argumentar uma incapacidade acidental.

A Incapacidade Acidental é um instituto jurídico previsto no Código Civil Português (Decreto-lei no 47.344 de 25 de novembro de 1966), que busca alcançar quem se encontra acidentalmente incapacitado por qualquer causa passageira que comprometa a sua faculdade intelectual e volitiva, sendo possível nestes casos, a anulação do ato jurídico praticado por esta pessoa.

Verifica-se, contudo, a dificuldade de ser notório os transtornos derivados do superendividamento, principalmente nos casos de consumo derivados de uma busca de realização pessoal, contudo, analisa-se, que quando se fala em empréstimos e concessões de financiamentos esse quadro poderia ser facilmente verificado pelas agência bancárias e órgãos de concessão de crédito, devido ao nível de informações integradas destes órgãos, o que geraria facilmente uma nulidade destes negócios com base em uma Incapacidade Acidental.

Diante da análise, conclui-se, portanto, que no Brasil a regulação da nulidade destes negócios jurídicos ocorre de modo diferente, não havendo ainda, uma atenção especial aos superendividados. Fato este que se evidencia como de urgente regulamentação e atenção, devido ao aumento significativo de superendividados na sociedade atual, sejam estas situações de endividamento geradas pela obtenção exacerbada de itens considerados supérfluos, seja pela obtenção de itens de primeira necessidade ou pelo empréstimo recorrente em instituições bancárias ou órgãos de crédito. Verifica-se ainda, a necessidade de uma regulamentação que conceda ao superendividado uma análise muito maior do que uma análise puramente econômica, mas uma análise socioambiental, que considere este sujeito em todas as suas dimensões, com todas as suas especificidades, uma regulamentação que trate não somente a causa, mas também os efeitos desta situação de superndividamento na vida destas pessoas, como expõe Jussara Maria Leal de Meirelles se faz importante reler categorias, revisar os conceitos, refletir "a respeito das disposições legais e dos fatos, sob o manto de valores tão fortes como a dignidade e a solidariedade. Somente assim é possível alcançar-se a compreensão verdadeira de quem, do quê e em que medida se pretende proteger". ${ }^{4}$

4 MEIRELLES, Jussara Maria Leal de. Meio Ambiente e Saúde Mental: uma perspectiva jurídica da solidariedade. CONPENDI MANAUS, p. 204. Disponível em:<http://www.publicadireito.com.br/conpedi/manaus/arquivos/anais/bh/jussara_maria_leal_de_ meirelles.pdf $>$. Acesso em; 22 de jun de 2018. 


\section{REFERÊNCIAS}

ARTIFON, Simone; PIVA, Maristela. Endividamento nos dias atuais: Fatores psicológicos implicados neste processo. Psocologia.pt - O PORTAL DOS PSICÓLOGOS. Disponível em:< http://www.psicologia.pt/artigos/textos/Ao771.pdf>. Acesso em; 19 de jun de 2018.

BAUMAN, Zygmunt. Vida líquida. 2. ed., rev. Rio de Janeiro: Zahar, 2009. Janeiro: Zahar, 2008.

Vida para consumo: a transformação das pessoas em mercadoria. Rio de

BRASIL, LEI № 13.105, DE 16 DE MARÇO DE 2015. Código de Processo Civil. Disponível em:< http://www.planalto.gov.br/ccivil_03/_ato2015-2018/2015/lei/l13105.htm>. Acesso em: o5 de jul de 2018.

BRASIL, LEI No 5.869, DE 11 DE JANEIRO DE 1973. Código de Processo Civil. Disponível em:< http://www.planalto.gov.br/ccivil_03/LEIS/L5869.htm\#livroiitituloiv >. Acesso em: o5 de jul de 2018.

CEZAR, Fernanda Moreira. O Consumidor Superendividado: por uma tutela jurídica à luz do direito civil-constitucional. Revista de Direito do Consumidor, São Paulo, n.63, jul.- set. 2007.

EARWICKER, Ray. The impacto f problem debt on health - a literature review. EQUITY ACTION - the EU Joint Action Programme on Health Inequalities. Disponível em: <http:// www.health-inequalities.eu/wp-content/uploads/2016/05/Problem-debt-and-health.pdf>. Acesso em: 05 de jul de 2018.

EFING, Antônio Carlos; OYAGUE, Olenka Woolcott; POLEWKA, Gabriele. A CRISE ECONÔMICA BRASILEIRA E O SUPERENDIVIDAMENTO DA POPULAÇÃO: EMERGÊNCIA DO APRIMORAMENTO LEGISLATIVO PARA TUTELA SOCIAL. Revista de Direito do Consumidor, v. 101, 2015.

HENNIGEN, Inês. Superendividamento dos consumidores: uma abordagem a partir da Psicologia Social.Revista Mal-estar e Subjetividade, Fortaleza, v.10, n. 4, dez. 2010, p. 1177. Disponível em: <http://pepsic.bvsalud.org/pdf/malestar/vion4/o6.pdf $>$. Acesso em: 22 de jun de 2018.

MEIRELLES, Jussara Maria Leal de. Meio Ambiente e Saúde Mental: uma perspectiva jurídica da solidariedade. CONPENDI - MANAUS. Disponível em:<http://www.publicadireito. com.br/conpedi/manaus/arquivos/anais/bh/jussara_maria_leal_de_meirelles.pdf $>$. Acesso em; 22 de jun de 2018.

PAFFARINI, Jacopo. COLOGNESE, Mariângela Matarazzo Fanfa. HAMEL, Eduardo Henrique. A insuficiência da responsabilidade socioambiental empresarial na perspectiva do desenvolvimento sustentável. Revista Direito e Desenvolvimento. Disponível em: < https:// periodicos.unipe.br/index.php/direitoedesenvolvimento/article/view/541/421>. Acesso em 29 de out. 2018. 
ROSA, Tais Hemann; ANDRADE, Fábio Siebeneichler. Notas Sobre a Tutela do Consumidor Superendividado no Brasil: um novo caso de proteção da pessoa contra si mesmo (atualidades e perspectivas). Arquivo Jurídico - Arquivo Jurídico - Teresina-PI - v. 2 - n. 1, jan./jun. de 2015. Disponível em: < file://C:/Users/caroline/Downloads/4508-15663-1-PB\%2o(2).pdf>. Acesso em: 05 de jul. de 2018.

SOUZA, Maristela Denise Marques. O comportamento do consumidor sob influência da publicidade. Revista da Ordem. Maio de 2018, no 48, p.41.CTBA- Paraná. 